\title{
A VIEW FROM THE WEST
}

I feel compelled to describe the events surrounding the development (?) of the Association of Carbon-14 Laboratories (ACL), from June 1988 to the present. It all started as Austin Long and I sat in the Secretariat of the Dubrovnik Palace Hotel and discussed ideas for offering the next conference in Tucson. I remember saying, "What we need is an organization to raise funds for travel expenses for those who do not have access to hard currency." Austin thought that was a fine idea, and said he would discuss it with Wim Mook, who should announce it at the Business Meeting.

We were disappointed that the proposal did not meet with too much enthusiasm, but we thought that the time was premature and further discussions were needed. Wim threw himself into the project with much energy and effort, and we, at RADIOCARBON, joined him. In April 1989, Wim visited Tucson, where we talked about the goals and functions of the ACL. These were:

1. Communication

2. Technical cooperation

3. Projects (such as conferences or workshops, publications)

4. Bringing together small, isolated laboratories

5. Sponsoring subsidized issues of RADIOCARBON

6. Fundraising for special projects (such as the IRDB)

7. Quality certification

Through our combined efforts, six laboratories have been receiving free subscriptions to RADIOCARBON for three years. The ACL also contributed $\$ 2500$ to the 14th International Radiocarbon Conference to cover travel expenses for colleagues who could not manage to attend without our help. Some laboratories have agreed to join this noble effort by contributing the cost of dating one sample per year. To date, the ACL has contributed about $\$ 3500$ to the radiocarbon community.

Wim's presentation in Tucson was greeted with less than optimism. Nonetheless, a committee was selected to prepare the way for officially establishing the ACL. Members of this committee met after the Business Meeting, but we have not heard of any results.

If RADIOCARBON is to be a vehicle of communication among the radiocarbon community, I recommend a discussion of this project in its pages. Three years between meetings, with no general discussions during the interval, is too long to accomplish any goals. If we are to wait for Glasgow to vote on the fate of the ACL, on the last day of the conference, with no discussions beforehand, we will not succeed.

The new ACL-East (this is our own, unofficial title) sets a good example for us to follow. The six points with which Austin Long has summarized their objectives indicate the urgent need for such an organization. I congratulate J.-M. Punning for his aggressive approach to the formation of this organization. Not only has the Presiding Board been elected, but also the by-laws have been drafted. Perhaps the Committee appointed at the Business Meeting of the Tucson conference should follow suit and call a workshop well before the Glasgow conference to discuss and implement, once and for all, the establishment of the ACL.

Your thoughts on the matter are more than welcome.

Renee Kra 